\title{
Assessment of bronchodilator responsiveness in preschool children using forced oscillations
}

\author{
Cindy Thamrin, Catherine L Gangell, Kanokporn Udomittipong, Merci M H Kusel, Hilary Patterson, \\ Takayoshi Fukushima, André Schultz, Graham L Hall, Stephen M Stick, Peter D Sly
}

See end of article for authors' affiliations

\section{Correspondence to:} Dr Peter D Sly, Telethon Institute for Child Health Research, P O Box 855, West Perth, WA 6872 Australia; peters@ichr.uwa. edu.au

Received 3 September 2006 Accepted 6 March 2007 Published Online First 13 March 2007

\begin{abstract}
Background: The forced oscillation technique (FOT) requires minimal patient cooperation and is feasible in preschool children. Few data exist on respiratory function changes measured using FOT following inhaled bronchodilators $(B D)$ in healthy young children, limiting the clinical applications of $B D$ testing in this age group. A study was undertaken to determine the most appropriate method of quantifying BD responses using FOT in healthy young children and those with common respiratory conditions including cystic fibrosis, neonatal chronic lung disease and asthma and/or current wheeze.

Methods: A pseudorandom FOT signal $(4-48 \mathrm{~Hz})$ was used to examine respiratory resistance and reactance at 6,8 and $10 \mathrm{~Hz} ; 3-5$ acceptable measurements were made before and $15 \mathrm{~min}$ after the administration of salbutamol. The post-BD response was expressed in absolute and relative (percentage of baseline) terms. Results: Significant BD responses were seen in all groups. Absolute changes in BD responses were related to baseline lung function within each group. Relative changes in $B D$ responses were less dependent on baseline lung function and were independent of height in healthy children. Those with neonatal chronic lung disease showed a strong baseline dependence in their responses. The BD response in children with cystic fibrosis, asthma or wheeze (based on both group mean data and number of responders) was not greater than in healthy children.

Conclusions: The BD response assessed by the FOT in preschool children should be expressed as a relative change to account for the effect of baseline lung function. The limits for a positive BD response of $-40 \%$ and $65 \%$ for respiratory resistance and reactance, respectively, are recommended.
\end{abstract}

$\mathrm{T}$ he forced oscillation technique (FOT) is increasingly used in preschool children to measure respiratory function owing to its low requirement for patient cooperation and ease of measurement. ${ }^{1}$ The technique allows measurement of the respiratory input impedance (Zrs) under tidal breathing conditions. From this, resistance (Rrs) and reactance (Xrs) of the respiratory system can be obtained as a function of frequency. Response in respiratory function to a bronchodilator (BD) is routinely used as part of the clinical assessment of children with lung disease, but little information exists on the $\mathrm{BD}$ response in preschool children with lung disease compared with healthy children as quantified by FOT variables.

Other lung function methods have been used to assess BD responses in children of this age group, both with and without lung disease, with mixed results. Spirometric parameters such as the forced expiratory volume in $1 \mathrm{~s}$ are variably dependent on airway diameter and compliance, both of which are potentially altered by $\mathrm{BD}$ inhalation but have opposite effects on maximal flow. ${ }^{2}$ The interrupter technique ${ }^{3-7}$ has been shown to underestimate resistance, particularly in children with high baseline resistance. ${ }^{8}$ Specific airway resistance obtained by whole body plethysmography ${ }^{90}$ has also been used in this age group.

There are a number of FOT studies using impulse oscillometry ${ }^{91}{ }^{12}$ but, because of the constraints of the technique, Rrs and Xrs are only reported at multiples of $5 \mathrm{~Hz}$, thus missing out on information from other frequencies. Studies in patients with cystic fibrosis (CF) have been made using pseudorandom FOT which have no such frequency constraints, but unfortunately they had no healthy group for comparison. ${ }^{2}$ Children of school age with neonatal chronic lung disease (nCLD) have been assessed using both impulse oscillometry ${ }^{13}$ and pseudorandom FOT, ${ }^{14}$ but preschool children were not included and the assessment did not include their BD response. Mazurek and colleagues $^{15}$ used the head generator technique to perform pseudorandom FOT on patients with asthma and $\mathrm{CF}$, but only reported Rrs and Xrs data from 10 and $20 \mathrm{~Hz}$ whereas Delacourt and coworkers ${ }^{8}$ used the extrapolated parameter $\mathrm{R}_{0}$ as an outcome variable. More recent studies assessing BD responses using FOT in healthy children and children with asthma ${ }^{9116}$ and in those with asthma only ${ }^{17}{ }^{18}$ have used impulse oscillometry.

The aim of this study was to characterise the BD response as assessed by pseudorandom FOT in healthy preschool children, and to compare this with children from different disease groups: CF, nCLD, and asthma and/or wheeze. The analysis was performed retrospectively from data collected as part of other ongoing studies. Using our findings, we aim to determine how $\mathrm{BD}$ responses in FOT parameters should be expressed and what constitutes a significant BD response.

\section{METHODS}

Subjects

Healthy children were defined as those with no history of asthma or wheeze ever and who had not been diagnosed with CF or nCLD. They were studied at a time when they were well and had had no respiratory infections in the 2 weeks before the date of study. As part of a separate study, they also underwent skin prick testing to locally relevant aeroallergens (house dust mite, cat, grass mix, mould mix) and their parents answered a questionnaire which yielded information on respiratory history and environmental tobacco smoke exposure. Atopy was defined as a positive skin prick test to one or more allergens where a

Abbreviations: $B D$, bronchodilator; $C F$, cystic fibrosis; FOT, forced oscillation technique; $\mathrm{nCLD}$, neonatal chronic lung disease; Rrs, respiratory resistance; $\mathrm{Xrs}$, respiratory reactance; Zrs, respiratory input impedance 
positive result was determined by a weal diameter of at least $3 \mathrm{~mm}$ after $15 \mathrm{~min}$.

Children with CF and nCLD were measured as part of clinical follow-up programmes at the Princess Margaret Hospital for Children. Children with CF were identified through neonatal screening or from clinical criteria and confirmed by sweat electrolyte analysis. Children with nCLD were those who required use of supplemental oxygen for more than 28 days at 36 weeks postmenstrual age for infants with gestational age at birth of $<32$ weeks and the use of supplemental oxygen at 28 days of life for individuals with gestational age at birth of $\geqslant 32$ weeks. ${ }^{19}$ Current wheeze was defined by the occurrence of episodes of wheezing in the past 12 months. Children with asthma were those with current wheeze who also had a doctor diagnosis of asthma.

Measurements were made in children when neither a longacting BD had been administered for at least $24 \mathrm{~h}$ nor a shortacting BD for at least $4 \mathrm{~h}$ before the testing session.

\section{Forced oscillation technique}

The FOT methods used in this study have been previously described and validated..$^{20}$ Respiratory impedance spectra (Zrs), yielding Rrs and Xrs as a function of frequency, were obtained using commercially available equipment (I2M, Chess Medical, Belgium) based on the specifications of Lándsér and coworkers, ${ }^{21}$ in accordance with European Respiratory Society guidelines. ${ }^{1}$ The forced oscillatory signal was a pseudorandom signal consisting of frequency components between 4 and $48 \mathrm{~Hz}$ with a measurement period of $8 \mathrm{~s}$.

\section{Protocol}

During measurement the child was seated comfortably upright with the neck in the neutral position and the arms resting comfortably by the side. The child's cheeks were supported by an investigator. Measurements were made with the child wearing a nose clip during quiet breathing through a mouthpiece and filter (Suregard, BirdHealthcare, Australia).

Three to five technically acceptable measurements were obtained at baseline. Individual measurements were considered technically unacceptable if coherence was $<0.95$ at three or more frequencies or if Zrs showed obvious artifacts.

Salbutamol $(600 \mu \mathrm{g})$ was administered via a pressurised metered dose inhaler (Ventolin, GlaxoSmithKline) and spacer device (Volumatic, GlaxoSmithKline). Respiratory function measurements were repeated (as above) 15 min after BD inhalation. All protocols used in this study were approved by the ethics committee at the Princess Margaret Hospital for Children and parental consent was obtained.

\section{Data analysis}

All technically acceptable Zrs measurements were averaged and mean Rrs and Xrs at 6, 8, and $10 \mathrm{~Hz}\left(\operatorname{Rrs}_{6}, \operatorname{Rrs}_{8}, \operatorname{Rrs}_{10}, \mathrm{Xrs}_{6}\right.$, $\mathrm{Xrs}_{8}$ and $\mathrm{Xrs}_{10}$ ) were calculated. Both absolute and relative BD responses were studied, where the relative $\mathrm{BD}$ response was the absolute $\mathrm{BD}$ response expressed as a percentage of baseline respiratory function.

With the BD response assessed by each FOT variable as the outcome, multiple linear regression analysis was performed, stratified by disease group, to determine the individual effects of the following factors on absolute and relative BD responses within each group: age, sex, height, weight, baseline lung function. These covariates were then also adjusted for in a multiple linear regression model used to compare the $\mathrm{BD}$ response in each disease group with the healthy group. All statistical analyses were performed at $\alpha=0.95$ using customised software (Intercooled Stata 8.1 for Windows, Stata Corporation, Texas, USA). Significance was defined as $\mathrm{p}<0.05$.

\section{RESULTS}

\section{Baseline and BD responses}

Anthropometric data and baseline respiratory function are shown in table 1. Children with nCLD were shorter and lighter than other children, most likely explaining the higher resistance and lower reactance at all frequencies compared with healthy children. Children with CF also had higher resistance (all frequencies) and lower reactance (at $6 \mathrm{~Hz}$ ) (table 1). There were no differences in baseline respiratory function between the children with asthma or wheeze and the healthy children (table 1). In all groups, post-BD lung function significantly improved compared with baseline, that is, the resistance parameters decreased while the reactance parameters increased (fig $1, p<0.05$ for all variables, Wilcoxon signed rank test).

Approximately one-third (24/78) of the healthy group were atopic and $17.9 \%$ (14/78) had been exposed to tobacco smoke. Neither atopy nor passive smoke exposure influenced baseline lung function, absolute or relative BD responses measured by any of the FOT variables ( $p>0.05$ for all tests, Mann-Whitney test).

\section{Dependence of BD responses on anthropometric factors and baseline lung function}

Stratified for disease group, the absolute response measured by all FOT variables was found to be strongly dependent on baseline lung function $(\mathrm{p}<0.001)$. The absolute response was not dependent on any of the other factors in any of the groups studied, with the exception of $\operatorname{Rrs}_{6}$ vs age in the healthy group (coefficient $=-0.058, \mathrm{p}=0.017), \mathrm{Xrs}_{6}$ vs age and sex in the CF

Table 1 Anthropometric data and baseline lung function of study subjects

\begin{tabular}{|c|c|c|c|c|c|}
\hline & $\begin{array}{l}\text { Healthy } \\
(n=78)\end{array}$ & $\begin{array}{l}\text { CF } \\
(n=39)\end{array}$ & $\begin{array}{l}\mathrm{nCLD} \\
(\mathrm{n}=49)\end{array}$ & $\begin{array}{l}\text { Asthma } \\
(n=56)\end{array}$ & $\begin{array}{l}\text { Wheeze } \\
(n=66)\end{array}$ \\
\hline Age (months) & $61(50,62)$ & $60(43,80)$ & $62(43,71)$ & $61(47,80)$ & $61(49,80)$ \\
\hline $\operatorname{Sex}(M: F)$ & $36: 42$ & $15: 24$ & $23: 26$ & $35: 21$ & $41: 25$ \\
\hline Height $(\mathrm{cm})$ & $110(103,118)$ & $107(94,122)$ & $106(96,113)$ & $112(101,123)$ & $112(102,22)$ \\
\hline Weight $(\mathrm{kg})$ & $19.5(15.8,22.6)$ & $17.8(14.2,24.7)$ & $16.4(13.9,19.9)$ & $20.0(15.7,26.3)$ & $20.0(16.0,25.1)$ \\
\hline \multicolumn{6}{|l|}{ Baseline lung function } \\
\hline $\begin{array}{l}\operatorname{Rrs}_{6}(\mathrm{hPa} / \mathrm{s} / \mathrm{l}) \\
\mathrm{Xrs}_{6}(\mathrm{hPa} / \mathrm{s} / \mathrm{l})\end{array}$ & $\begin{array}{c}7.69(5.53,11.78) \\
-2.83(-4.88,-1.36)\end{array}$ & $\begin{array}{c}9.03(6.66,11.30) \\
-3.51(-5.23,-2.24)\end{array}$ & $\begin{array}{l}11.12(8.16,14.29) \\
-4.90(-6.78,-3.43)\end{array}$ & $\begin{array}{c}8.17(5.67,13.06) \\
-3.18(-5.67,-1.44)\end{array}$ & $\begin{array}{c}8.03(5.65,12.84) \\
-3.12(-5.44,-1.42)\end{array}$ \\
\hline $\mathrm{Rrs}_{8}(\mathrm{hPa} / \mathrm{s} / \mathrm{l})$ & $7.58(5.54,10.68)$ & $8.94(6.45,11.34)$ & $10.49(7.61,13.31)$ & $8.06(5.69,13.08)$ & $7.84(5.66,12.69)$ \\
\hline $\mathrm{Xrs}_{8}(\mathrm{hPa} / \mathrm{s} / \mathrm{l})$ & $-2.44(-4.52,-1.51)$ & $-2.82(-5.66,-1.50)$ & $-4.08(-5.74,-2.73)$ & $-2.50(-5.55,-1.01)$ & $-2.35(-5.10,-1.13)$ \\
\hline $\operatorname{Rrs}_{10}(\mathrm{hPa} / \mathrm{s} / \mathrm{l})$ & $7.17(5.44,10.37)$ & $8.32(6.15,10.52)$ & $9.66(7.19,11.79)$ & $7.67(5.47,11.80)$ & $7.42(5.42,11.36)$ \\
\hline $\mathrm{Xrs}_{10}(\mathrm{hPa} / \mathrm{s} / \mathrm{l})$ & $-2.57(-4.65,-1.46)$ & $-2.75(-5.10,-1.40)$ & $-4.03(-5.86,-2.46)$ & $-2.44(-5.28,-1.04)$ & $-2.46(-5.24,-1.06)$ \\
\hline
\end{tabular}

Continuous data are represented as median (10th, 90th percentile) values. Numbers in bold indicate a significant difference compared with the healthy group (MannWhitney test for each group, $\mathrm{p}<0.05$ ).

$\mathrm{CF}$, cystic fibrosis; $\mathrm{nCLD}$, neonatal chronic lung disease; $\mathrm{Rrs}_{6}$, $\mathrm{Rrs}_{8}, \mathrm{Rrs}_{10}$, respiratory resistance at 6,8 and $10 \mathrm{~Hz}$; $\mathrm{Xrs}_{6}, \mathrm{Xrs}_{8}$, and $\mathrm{Xrs}_{10}$, respiratory reactance at 6,8 and $10 \mathrm{~Hz}$. 

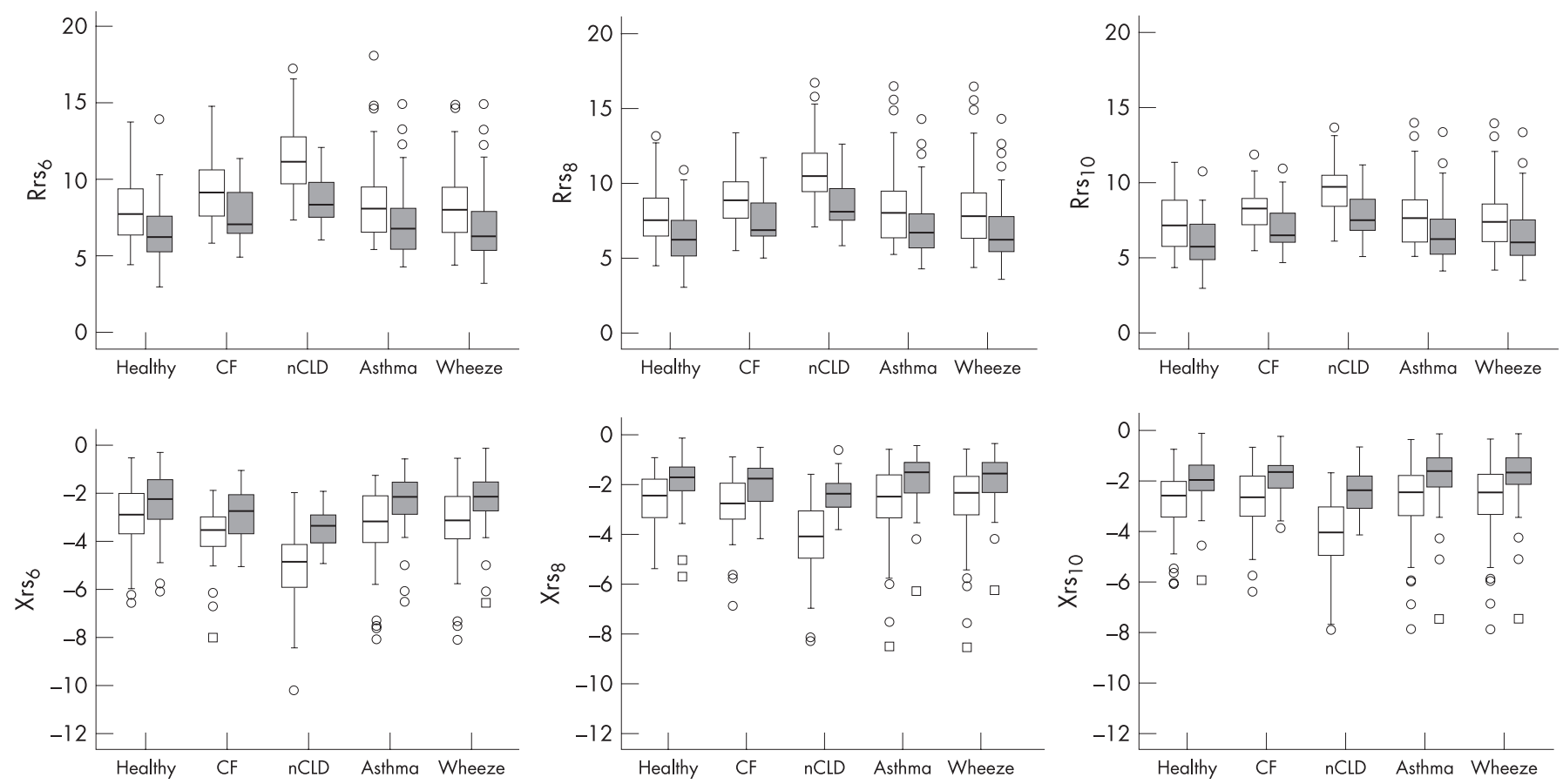

Figure 1 Pre- and post-bronchodilator responses in all groups measured by resistance (Rrs) and reactance (Xrs) at 6, 8 and $10 \mathrm{~Hz}$. Open circles and squares indicate outliers and extreme values, respectively. Post-bronchodilator responses (shaded boxplots) were significantly different from prebronchodilator responses (clear boxplots) for all parameters in all groups ( $p<0.05$, Wilcoxon signed rank test). CF, cystic fibrosis; $\mathrm{nCLD}$, neonatal chronic lung disease.
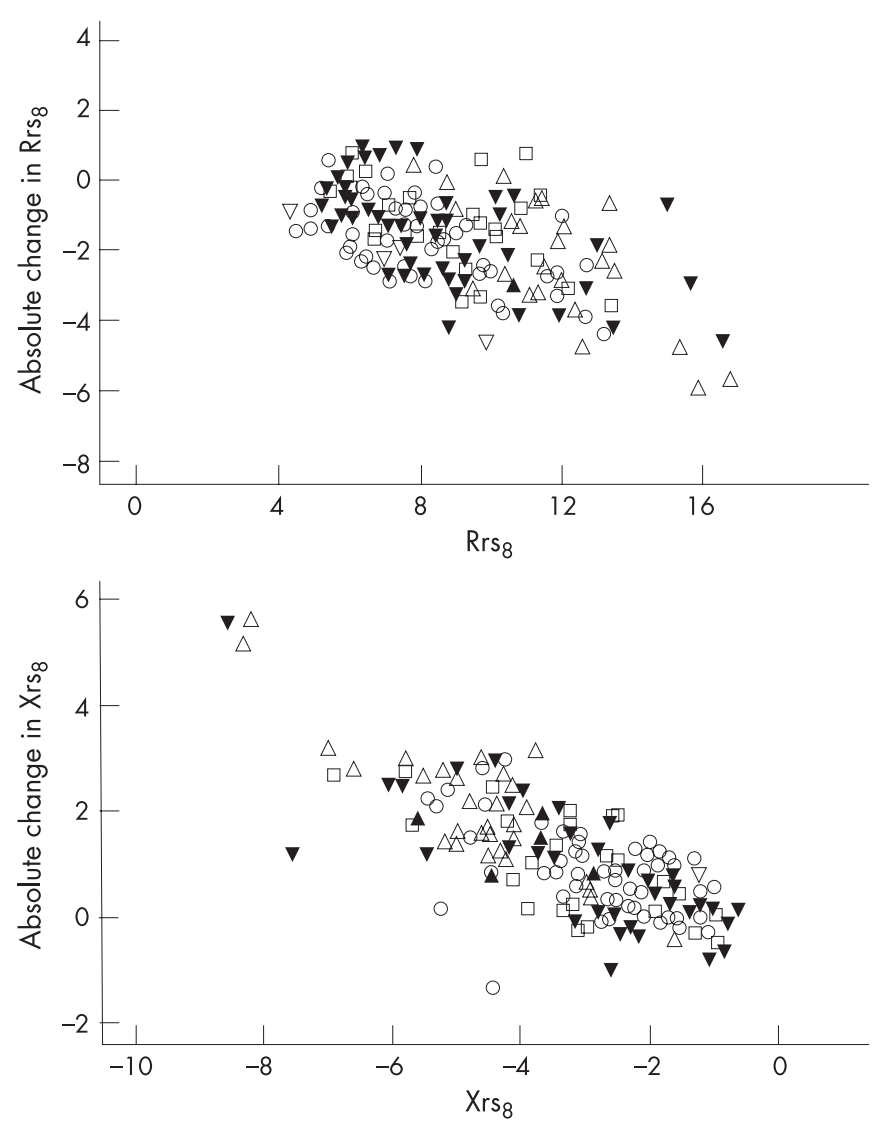

Figure 2 Absolute bronchodilator response plotted against baseline for resistance (Rrs) and reactance (Xrs) at $8 \mathrm{~Hz}$. Different symbols indicate different groups (circles, healthy; squares, cystic fibrosis; up triangles, neonatal chronic lung disease; down triangles (solid), asthma; down triangles (open), wheeze only. group (regression slope coefficient $=-0.046, \mathrm{p}=0.010$ and coefficient $=0.520, \mathrm{p}=0.039$, respectively), $\mathrm{Xrs}_{8}$ vs weight in the nCLD group (coefficient $=-0.150, \mathrm{p}=0.027$ ), and $\mathrm{Xrs}_{10}$ vs height in the wheeze group (coefficient $=0.072, \mathrm{p}=0.026$ ). Scatter graphs for $\mathrm{Rrs}_{8}$ and $\mathrm{Xrs}_{8}$ plotted against baseline (fig 2) were representative of the relationships between FOT variables and baseline in general.

Stratified for disease group, the relative response measured by all FOT variables was less significantly dependent on baseline lung function (significant $\mathrm{p}$ values ranging from $<0.001$ to 0.45 ), with no relationship between baseline and $\mathrm{Rrs}_{8}, \mathrm{Rrs}_{10}$ or $\mathrm{Xrs}_{6}$ in the healthy group and $\mathrm{Rrs}_{10}$ in the CF group. In addition, $\mathrm{Xrs}_{6}$ vs age in the CF group (coefficient $=-1.14, \mathrm{p}=0.036), \mathrm{Xrs}_{8}$ vs weight in the nCLD group (coefficient $=4.11, \mathrm{p}=0.020)$ and $\mathrm{Xrs}_{10}$ in the wheeze group (coefficient $=2.67, \mathrm{p}=0.018$ ) were found to be significant.

\section{Comparison of relative BD responses between healthy and disease groups}

Results from comparisons between healthy and disease groups, adjusted for age, sex, height, weight and baseline, were similar for the absolute (table 2) and relative (table 3) BD responses. For the sake of simplicity, only the relative responses are described here.

As a group, children with CF tended to have smaller relative BD responses than healthy children. Adjusted for covariates, $\mathrm{Rrs}_{8}$ and $\operatorname{Rrs}_{10}$ were found to be significantly different from the healthy group (adjusted $\mathrm{p}=0.031$ and 0.021 , respectively). There were no significant differences in relative BD assessed by any of the FOT parameters between children with CF who did (53\%) or did not have $(47 \%)$ respiratory symptoms (parental reported cough, cold or sputum production or clinician reported wheeze, crackles or respiratory tract infection) at the time of the study.

Children with nCLD as a group tended to have larger relative $\mathrm{BD}$ responses than healthy children, with a weakly significant difference in $\mathrm{Rrs}_{8}$ and $\mathrm{Rrs}_{10}$ from the healthy group (adjusted $p=0.045$ and 0.042 , respectively). In this group, baseline 
Table 2 Absolute bronchodilator responses

\begin{tabular}{|c|c|c|c|c|c|}
\hline & $\begin{array}{l}\text { Healthy } \\
(n=78)\end{array}$ & $\begin{array}{l}\text { CF } \\
(n=39)\end{array}$ & $\begin{array}{l}n C L D \\
(n=49)\end{array}$ & $\begin{array}{l}\text { Asthma } \\
(n=56)\end{array}$ & $\begin{array}{l}\text { Wheeze } \\
(n=66)\end{array}$ \\
\hline$\Delta \mathrm{Rrs}_{6}$ (hPa.s/l) & $-1.51(-3.69,-0.17)$ & $-1.46(-3.18,-0.04)$ & $-2.44(-4.14,-0.98)$ & $-1.17(-4.10,0.58)$ & $-1.28(-4.03,0.51)$ \\
\hline$\Delta \mathrm{Xrs}_{6}$ (hPa.s/l) & $0.57(-0.27,1.66)$ & $0.86(-0.16,2.05)$ & $1.49(0.15,3.05)$ & $0.84(-0.21,2.30)$ & $0.84(-0.14,2.33)$ \\
\hline$\Delta \operatorname{Rrs}_{8}$ (hPa.s/l) & $-1.44(-2.73,-0.30)$ & $-1.30(-3.13,0.28)$ & $-1.94(-3.78,-0.54)$ & $-1.09(-3.39,0.59)$ & $-1.09(-3.39,0.53)$ \\
\hline$\Delta \mathrm{Xrs}_{8}(\mathrm{hPa} . \mathrm{s} / \mathrm{l})$ & $0.75(-0.04,1.82)$ & $0.75(-0.17,2.06)$ & $1.51(0.47,2.98)$ & $0.79(-0.13,2.47)$ & $0.79(-0.13,2.47)$ \\
\hline$\Delta \mathrm{Rrs}_{10}(\mathrm{hPa} . \mathrm{s} / \mathrm{l})$ & $-1.34(-2.55,-0.21)$ & $-1.24(-2.62,0.30)$ & $-1.76(-3.03,-0.46)$ & $-0.89(-2.90,0.29)$ & $-0.95(-2.90,0.24)$ \\
\hline$\Delta \mathrm{Xrs}_{10}$ (hPa.s/l) & $0.73(-0.00,2.03)$ & $0.73(0.00,1.99)$ & $1.61(0.36,3.08)$ & $0.67(-0.12,2.22)$ & $0.71(0.00,2.14)$ \\
\hline
\end{tabular}

Data shown as median absolute change with bronchodilator (10th, 90 th percentiles). Numbers in bold indicate a significant difference compared with the healthy group ( $p<0.05$, multiple linear regression for each group adjusted for covariates).

$\mathrm{CF}$, cystic fibrosis; $\mathrm{nCLD}$, neonatal chronic lung disease; $\operatorname{Rrs}_{6}, \operatorname{Rrs}_{8}, \operatorname{Rrs}_{10}$, respiratory resistance at 6,8 and $10 \mathrm{~Hz}$; $\mathrm{Xrs}_{6}, \mathrm{Xrs}_{8}$, and $\mathrm{Xrs}_{10}$, respiratory reactance at 6, 8 and $10 \mathrm{~Hz}$.

remained a significant covariate in the multiple linear regression model for all FOT variables.

Children with a doctor diagnosis of asthma showed significant differences from the healthy group in $\mathrm{BD}$ responses assessed by $\operatorname{Rrs}_{6}, \operatorname{Rrs}_{8}$ and $\operatorname{Rrs}_{10}$ (adjusted $\mathrm{p}=0.008,0.004$ and 0.002 , respectively) but not by any of the Xrs variables. Similar results with weaker significance were seen in children with wheeze (adjusted p $=0.049,0.010$ and 0.004, respectively for $\operatorname{Rrs}_{6}, \operatorname{Rrs}_{8}$ and $\left.\operatorname{Rrs}_{10}\right)$. In this group, Rrs responses tended to be smaller than in healthy children while Xrs responses tended to be larger, although again the latter were not significant.

\section{Significant relative $B D$ response}

The characteristics of the healthy group were used to determine what constitutes a significant $\mathrm{BD}$ response. As the $\mathrm{BD}$ response was significantly dependent on baseline lung function, these analyses were only undertaken using relative $\mathrm{BD}$ responses. To the nearest percentage change, the limits of agreement for relative $\mathrm{BD}$ responses in the healthy group were set to be $-42 \%$, $-37 \%$ and $-39 \%$ for $\mathrm{Rrs}_{6}, \mathrm{Rrs}_{8}$ and $\mathrm{Rrs}_{10}$, respectively (taken from the 5 th percentiles), and $61 \%, 67 \%$ and $63 \%$ for $\mathrm{Xrs}_{6}, \mathrm{Xrs}_{8}$, and $\mathrm{Xrs}_{10}$, respectively (taken from the 95 th percentiles).

Using these criteria, the number of subjects who responded significantly to BD (ie, who had a response greater than these limits) was counted within each of the disease groups (table 4). While the number of responders in each disease group did not differ significantly in comparison with the healthy group ( $p>0.05$, Fisher exact test), the reactance parameters tended to yield more responders than the resistance parameters.

\section{DISCUSSION}

The results of this study show that the magnitude of the change in lung function following BD inhalation measured with pseudorandom FOT in preschool children is strongly related to baseline lung function. This is true for healthy children and those with lung disease. Reporting $\mathrm{BD}$ responses relative to baseline lung function (ie, as a percentage of baseline) accounts for this effect to some extent.

\section{Characterisation of $B D$ responses}

The magnitude of the $\mathrm{BD}$ responses presented in this study at 6 and $10 \mathrm{~Hz}\left(-21 \%\right.$ for $\mathrm{Rrs}_{6}, 27 \%$ for $\mathrm{Xrs}_{6},-19 \%$ for $\mathrm{Rrs}_{10}$ and $29 \%$ for $\mathrm{Xrs}_{10}$ ) compare well with data measured using impulse oscillometry at 5 and $10 \mathrm{~Hz}$ by Malmberg and coworkers (-19.2\% for $\mathrm{Rrs}_{5}$ and $-19 \%$ for $\left.\operatorname{Rrs}_{10}\right){ }^{.12}$ They also reported a change of 0.64 and $0.60 \mathrm{hPa} . \mathrm{s} / \mathrm{l}$ for $\mathrm{Xrs}_{5}$ and $\mathrm{Xrs}_{10}$, respectively (relative changes not provided), similar to the 0.57 and $0.73 \mathrm{hPa} . \mathrm{s} / \mathrm{l}$ for $\mathrm{Xrs}_{6}$ and $\mathrm{Xrs}_{10}$, respectively, seen in our study. In contrast, Hellinckx and colleagues $^{11}\left(-13 \%\right.$ for $\mathrm{Rrs}_{5}$ and $15 \%$ for $\left.\mathrm{Xrs}_{5}\right)$ and Nielsen and Bisgaard ${ }^{9}\left(-10 \%\right.$ for $\mathrm{Rrs}_{5}$ and $14 \%$ for $\mathrm{Xrs}_{5}$ ) both reported smaller changes in lung function following BD inhalation. There was a large spread of BD responses in our groups, as was the case in the other previously published studies.

Our finding that the $\mathrm{BD}$ response as assessed by FOT parameters at 6,8 and $10 \mathrm{~Hz}$ is related to its corresponding value at baseline is consistent with that of Hellinckx and coworkers ${ }^{11}$ who also found a correlation between absolute BD response and baseline lung function in total Rrs and Xrs. ${ }^{16} 2223$

While baseline lung function is generally known to be dependent on height, we found that the BD response as measured by FOT variables was height-independent (with the exception of $\mathrm{Xrs}_{10}$ in wheeze), irrespective of whether it is expressed as an absolute or a relative response.

The children were generally studied at times when they were clinically stable and asymptomatic. One reason for including children from the various disease groups was to determine whether the underlying disease increased the short-term variability of FOT. In general, our data show that the criteria for determining the $\mathrm{BD}$ response in healthy children are also valid for children with CF, nCLD, asthma and current wheeze. There is a suggestion from our data that FOT parameters at $6 \mathrm{~Hz}$ (specifically $\mathrm{Xrs}_{6}$ ) may be the most appropriate for expressing the $\mathrm{BD}$ response in preschool children. Reactance

Table 3 Relative (\% baseline) bronchodilator responses

\begin{tabular}{|c|c|c|c|c|c|}
\hline & $\begin{array}{l}\text { Healthy } \\
(n=78)\end{array}$ & $\begin{array}{l}\text { CF } \\
(n=39)\end{array}$ & $\begin{array}{l}n C L D \\
(n=49)\end{array}$ & $\begin{array}{l}\text { Asthma } \\
(n=56)\end{array}$ & $\begin{array}{l}\text { Wheeze } \\
(n=66)\end{array}$ \\
\hline$\Delta \mathrm{Rrs}_{6}(\%)$ & $-21.3(-35.0,-3.1)$ & $-16.8(-32.1,-0.6)$ & $-23.3(-33.0,-9.2)$ & $-14.9(-37.0,8.8)$ & $-16.0(-37.9,8.4)$ \\
\hline$\Delta \mathrm{Xrs}_{6}(\%)$ & $27.4(-7.5,50.0)$ & $23.5(-5.1,46.7)$ & $31.9(4.0,49.8)$ & $27.0(-13.8,57.3)$ & $28.4(-6.5,59.9)$ \\
\hline$\Delta \mathrm{Rrs}_{8}(\%)$ & $-18.7(-35.0,-4.4)$ & $-14.8(-26.7,4.1)$ & $-19.2(-33.0,-5.2)$ & $-16.0(-33.1,9.7)$ & $-16.3(-33.1,8.9)$ \\
\hline$\Delta \mathrm{Xrs}_{8}(\%)$ & $30.9(-1.6,62.6)$ & $30.0(-6.5,56.1)$ & $38.8(16.4,63.2)$ & $30.3(-7.8,58.9)$ & $32.2(-7.8,60.9)$ \\
\hline$\Delta \operatorname{Rrs}_{10}(\%)$ & $-18.8(-32.3,-3.7)$ & $-15.0(-26.8,4.3)$ & $-18.2(-27.5,-4.9)$ & $-14.7(-33.4,4.5)$ & $-15.3(-33.4,3.0)$ \\
\hline$\Delta \mathrm{Xrs}_{10}(\%)$ & $29.3(-0.2,53.9)$ & $29.4(0.3,53.6)$ & $35.5(14.3,56.9)$ & $32.7(-7.0,57.5)$ & $33.9(0.0,58.4)$ \\
\hline
\end{tabular}

Data shown as median relative change with bronchodilator (10th, 90th percentile). Numbers in bold indicate a significant difference compared with the healthy group ( $p<0.05$, multiple linear regression for each group adjusted for covariates).

$\mathrm{CF}$, cystic fibrosis; $\mathrm{nCLD}$, neonatal chronic lung disease; $\operatorname{Rrs}_{6}$, $\operatorname{Rrs}_{8}$, Rrs 10 , respiratory resistance at 6,8 and $10 \mathrm{~Hz}$; $\mathrm{Xrs}_{6}, \mathrm{Xrs}_{8}$, and $\mathrm{Xrs}_{10}$, respiratory reactance at 6, 8 and $10 \mathrm{~Hz}$. 
Table 4 Number of subjects in each group showing a significant relative bronchodilator response as determined by the limits of the healthy group for resistance (Rrs) and reactance (Xrs) at 6, 8 and $10 \mathrm{~Hz}$

\begin{tabular}{llllll}
\hline & Healthy & CF & nCLD & Asthma & Wheeze \\
\hline$\left|\Delta \operatorname{Rrs}_{6}\right|>42 \%$ & $3 / 68(4.4 \%)$ & $0 / 36(0.0 \%)$ & $1 / 49(2.0 \%)$ & $2 / 53(3.8 \%)$ & $3 / 61(4.9 \%)$ \\
$\left|\Delta \mathrm{Xrs}_{6}\right|>61 \%$ & $3 / 68(4.4 \%)$ & $1 / 36(2.8 \%)$ & $0 / 49(0.0 \%)$ & $2 / 53(3.8 \%)$ & $5 / 61(8.2 \%)$ \\
$\left|\Delta \operatorname{Rrs}_{8}\right|>37 \%$ & $3 / 78(3.8 \%)$ & $1 / 38(2.6 \%)$ & $2 / 49(4.1 \%)$ & $1 / 55(1.8 \%)$ & $2 / 65(3.1 \%)$ \\
$\left|\Delta \mathrm{Xrs}_{8}\right|>67 \%$ & $4 / 78(5.1 \%)$ & $2 / 38(5.3 \%)$ & $2 / 49(4.1 \%)$ & $2 / 55(3.6 \%)$ & $3 / 65(4.6 \%)$ \\
$\left|\Delta \operatorname{Rrs}_{10}\right|>39 \%$ & $3 / 78(3.8 \%)$ & $0 / 38(0.0 \%)$ & $0 / 49(0.0 \%)$ & $1 / 56(1.8 \%)$ & $1 / 66(1.5 \%)$ \\
$\left|\Delta \mathrm{Xrs}_{10}\right|>63 \%$ & $3 / 78(3.8 \%)$ & $1 / 38(2.6 \%)$ & $3 / 49(6.1 \%)$ & $2 / 56(3.6 \%)$ & $2 / 66(3.0 \%)$ \\
\hline
\end{tabular}

$C F$, cystic fibrosis; $n C L D$, neonatal chronic lung disease; $|\Delta R r s|$, refers to the absolute change in Rrs.

has been shown to be a more sensitive indicator of airway obstruction..$^{22}$ It is plausible that this applies to reversibility of airway obstruction as well.

Based on the results from our healthy group, the criteria for defining a significant BD response are similar for both Rrs and Xrs at 6, 8 and $10 \mathrm{~Hz}$ (table 4). A fall in Rrs of $40 \%$ and an increase in Xrs of $65 \%$ appear to be suitable criteria for defining a $\mathrm{BD}$ response. Our data do show that the $6 \mathrm{~Hz}$ data point was more often unavailable due to low coherence $(55 / 252,21.8 \%$ ) than either the $8 \mathrm{~Hz}(40 / 252,15.9 \%)$ or the $10 \mathrm{~Hz}(39 / 252$, $15.5 \%)$ data point. Thus, $\mathrm{Rrs}_{8}$ and $\mathrm{Xrs}_{8}$ may offer the best balance between sensitivity and reliability for assessing BD responses in preschool children. The BD criteria proposed here are similar to those previous suggested in studies using impulse oscillometry. Hellinckx and coworkers ${ }^{11}$ set the cut-off for $\mathrm{Rrs}_{5}$ at $-41 \%$. Similarly, Malmberg and coworkers ${ }^{12}$ proposed $-37 \%$ and $-34 \%$ as cut-off points for $\mathrm{Rrs}_{5}$ and $\mathrm{Rrs}_{10}$, respectively. Nielsen and Bisgaard ${ }^{9}$ found the 5 th percentile for BD response in $\mathrm{Rrs}_{5}$ to be much lower at $-28 \%$. The corresponding cut-off point for $\mathrm{Xrs}_{5}$ was $-42 \%$.

\section{Cystic fibrosis}

As a group, the children with CF in this study did not exhibit a greater $\mathrm{BD}$ response in resistance and showed no difference in the $\mathrm{BD}$ response in reactance compared with healthy children. We also found that there were no significant differences in the number of responders between health and CF, irrespective of symptomatic status. This compares well with a longitudinal study by Nielsen and coworkers ${ }^{10}$ in which no differences in BD responsiveness were found between healthy children and children with CF as measured by specific airway resistance. The authors also looked at impulse oscillometry and found $\mathrm{Xrs}_{5}$ to yield a statistically significant greater BD response in CF but dismissed this as a type I error. Note that when using the Zscore for $\mathrm{Xrs}_{5}$ as a criterion, the authors found $20 \%$ of children with CF exhibited a positive BD response on their first visit and $16 \%$ on their second visit. However, none of the FOT results were expressed as relative changes (the FOT results were expressed as an absolute change in Z-score), so any effects of baseline magnitude were not adjusted for. In another study Hellinckx and coworkers ${ }^{2}$ looked at $\mathrm{Rrs}_{6}$ and determined that 13 of 20 patients with CF had a favourable response to BD but used a cut-off of $-12 \%$ obtained from the within-subject variability of the CF group itself, which was much smaller than the limits of the BD response used in this study.

\section{Neonatal chronic lung disease}

To our knowledge, no FOT data on the BD response in preschool children with nCLD have been published. Our data show that, even when expressed as a percentage of the higher baseline values, BD responses in nCLD tend to be larger than those in healthy children and still showed a significant dependence on baseline respiratory function. Baseline was found to be a particularly strong covariate in this disease group, and was also largely responsible for any apparent differences in the BD response. This is perhaps not surprising given the difference in height and weight between the children with nCLD and the healthy group. In effect, we conclude that there were no differences in BD response between the healthy children and those with nCLD in our study. A previous study ${ }^{24}$ found that children of school age with nCLD had significantly higher BD responsiveness than controls, as assessed using spirometry. We are unaware of equivalent studies in preschool children to enable us to compare any differences that may be revealed between spirometry and FOT.

\section{Asthma/wheeze}

On grouped data, the BD response assessed by the Rrs variables was not larger in the asthma or wheeze groups than in healthy children and, in fact, tended to be smaller when adjusted for covariates. There were no significant differences in the BD response assessed by the Xrs variables. Hellinckx and coworkers $^{11}$ found no differences in BD responses at $\mathrm{Rrs}_{5}$ and Rrs $_{10}$ between healthy children and children with stable asthma who had normal baseline lung function. When considered as individuals, more children with wheeze in our study had a BD response outside the limits of the healthy group when this response was assessed using $\mathrm{Xrs}_{6}$. Only 11 of the 66 children in the wheeze group did not have persistent wheeze (defined in this case by wheeze before the past 12 months in addition to within the past 12 months), indicating that these children probably had asthma despite a lack of diagnosis from a doctor. However, all children were asymptomatic at the time of the lung function studies. The absence of differences in baseline lung function and in BD responses between these children and the healthy group is therefore not surprising. One study using the interrupter technique has shown increased BD responses in wheezy preschool children compared with past wheezers, ${ }^{25}$ but this study involved children who had had a recent exacerbation and were likely to have more severe asthma than the children in our asthma group. Another interrupter study found a great degree of overlap between healthy preschool children and those with asthma, although the dosage used was much lower than that used in our study. ${ }^{6}$ There is also a possibility that the higher dosage used in our study, which is normally used for BD testing in our laboratory, contributed to the differences in these and other previous studies. Furthermore, it should be pointed out that some of the children in our asthma or wheeze group would have been on inhaled corticosteroids. Characterisations of the BD response in symptomatic and asymptomatic asthma, or in children from whom inhaled corticosteroids are withheld, are beyond the scope of the present study.

In summary, the data from the present study show that the magnitude of the BD responses in preschool children measured using pseudorandom FOT is strongly influenced by baseline lung function. Changes in lung function should therefore be reported as a percentage of baseline to alleviate this effect. The best balance between responsiveness and reliability appears to 
be provided by $\mathrm{Rrs}_{8}$ and $\mathrm{Xrs}_{8}$. A fall in Rrs of $40 \%$ or an increase in Xrs of $65 \%$ are indicative of significant changes in respiratory function following BD inhalation. Further systematic studies are required to determine the clinical significance of post-BD changes in lung function in preschool children with lung disease.

\section{Authors' affiliations \\ Catherine L Gangell, Hilary Patterson, André Schultz, Graham L Hall, \\ Stephen M Stick, Respiratory Medicine, Princess Margaret Hospital for Children, Perth, Australia}

Cindy Thamrin, Kanokporn Udomittipong, Merci M H Kusel, Takayoshi

Fukushima, Peter D Sly, Telethon Institute for Child Health Research, Centre for Child Health Research, University of Western Australia, Perth, Australia

This work is supported by grants from the National Health and Medical Research Committee, Australia, the National Institutes of Health, USA and the Asthma Foundation of Western Australia. KU was supported by a grant from the Siriraj Hospital, Thailand.

Competing interests: None.

\section{REFERENCES}

1 Oostveen E, MacLeod D, Lorino $H$, et al. The forced oscillation technique in clinical practice: methodology, recommendations and future developments. Eur Respir J 2003;22:1026-41.

2 Hellinckx J, De Boeck K, Demedts M. No paradoxical bronchodilator response with forced oscillation technique in children with cystic fibrosis. Chest 1998; 113:55-9.

3 Bridge PD, Ranganathan S, McKenzie SA. Measurement of airway resistance using the interrupter technique in preschool children in the ambulatory setting. Eur Respir J 1999;13:792-6.

4 Beydon N, Amsallem F, Bellet $M$, et al. Pulmonary function tests in preschool children with cystic fibrosis. Am J Respir Crit Care Med 2002;166:1099-104.

5 Beydon N, Amsallem F, Bellet M, et al. Pre/postbronchodilator interrupter resistance values in healthy young children. Am J Respir Crit Care Med 2002; 165:1388-94.

6 Beydon N, Pin I, Matran R, et al. Pulmonary function tests in preschool children with asthma. Am J Respir Crit Care Med 2003;168:640-4.

7 Phagoo SB, Wilson NM, Silverman M. Evaluation of a new interrupter device for measuring bronchial responsiveness and the response to bronchodilator in 3 year old children. Eur Respir J 1996;9:1374-80.

8 Delacourt $\mathrm{C}$, Lorino $\mathrm{H}$, Fuhrman $\mathrm{C}$, et al. Comparison of the forced oscillation technique and the interrupter technique for assessing airway obstruction and its reversibility in children. Am J Respir Crit Care Med 2001;164:965-72.
9 Nielsen KG, Bisgaard H. Discriminative capacity of bronchodilator response measured with three different lung function techniques in asthmatic and healthy children aged 2 to 5 years. Am J Respir Crit Care Med 2001 ;164:554-9.

10 Nielsen KG, Pressler T, Klug B, et al. Serial lung function and responsiveness in cystic fibrosis during early childhood. Am J Respir Crit Care Med 2004;169:1209-16.

11 Hellinckx J, De Boeck K, Bande-Knops J, et al. Bronchodilator response in 3-6.5 years old healthy and stable asthmatic children. Eur Respir J 1998;12:438-43.

12 Malmberg LP, Pelkonen A, Poussa T, et al. Determinants of respiratory system input impedance and bronchodilator response in healthy Finnish preschool children. Clin Physiol Funct Imaging 2002;22:64-71.

13 Malmberg LP, Mieskonen S, Pelkonen A, et al. Lung function measured by the oscillometric method in prematurely born children with chronic lung disease. Eur Respir J 2000;16:598-603.

14 Duiverman EJ, Den Boer JA, Roorda RJ, et al. Lung function and bronchial responsiveness measured by forced oscillometry after bronchopulmonary dysplasia. Arch Dis Child 1988;63(7 Spec No):727-32.

15 Mazurek HK, Marchal F, Derelle J, et al. Specificity and sensitivity of respiratory impedance in assessing reversibility of airway obstruction in children. Chest 1995; 107:996-1002.

16 Marotta A, Klinnert MD, Price MR, et al. Impulse oscillometry provides an effective measure of lung dysfunction in 4 -year-old children at risk for persistent asthma. J Allergy Clin Immunol 2003;112:317-22.

17 Olaguibel JM, Alvarez-Puebla MJ, Anda M, et al. Comparative analysis of the bronchodilator response measured by impulse oscillometry (IOS), spirometry and body plethysmography in asthmatic children. J Investig Allergol Clin Immunol 2005; 15:102-6.

18 Ortiz G, Menendez R. The effects of inhaled albuterol and salmeterol in 2- to 5year-old asthmatic children as measured by impulse oscillometry. J Asthma 2002;39:531-6.

19 Jobe AH, Bancalari E. Bronchopulmonary dysplasia. Am J Respir Crit Care Med $2001 ; 163: 1723-9$

20 Hall GL, Sly PD, Fukushima T, et al. Respiratory function in healthy young children using forced oscillations. Thorax 2007;62:521-6.

21 Landser FJ, Nagles J, Demedts $M$, et al. A new method to determine frequency characteristics of the respiratory system. J Appl Physiol 1976;41:101-6.

22 Klug B, Bisgaard H. Measurement of lung function in awake 2-4-year-old asthmatic children during methacholine challenge and acute asthma: a comparison of the impulse oscillation technique, the interrupter technique, and transcutaneous measurement of oxygen versus whole-body plethysmography Pediatr Pulmonol 1996:21:290-300.

23 Bouaziz N, Beyaert C, Gauthier R, et al. Respiratory system reactance as an indicator of the intrathoracic airway response to methacholine in children. Pediatr Pulmonol 1996;22:7-13.

24 Gross SJ, lannuzzi DM, Kveselis DA, et al. Effect of preterm birth on pulmonary function at school age: a prospective controlled study. J Pediatr 1998;133:188-92.

25 McKenzie S, Bridge $P$, Healy M. Airway resistance and atopy in preschool children with wheeze and cough. Eur Respir J 2000;15:833-8.

\section{LUNG ALERT}

\section{Emergence of influenza $B$ viruses with reduced sensitivity to neuraminidase inhibitors}

$\Delta$ Emergence of influenza B viruses with reduced sensitivity to neuraminidase inhibitors. Hatakeyama $S$, Sugaya $N$, Ito $M$, et al. JAMA 2007;297:1435-42.

O seltamivir is a neuraminidase inhibitor effective in the treatment of influenza. In this Japanese study, the sensitivity of influenza B virus to neuraminidase inhibitors was assessed in 74 children before and after treatment with oseltamivir, and in a further 348 untreated patients, 66 of whom were adults.

They found that one patient treated with oseltamivir had a variant of influenza B virus with reduced neuraminidase inhibitor sensitivity. Among the untreated group, seven (1.7\%) had variants with reduced sensitivity, due to a number of different mutations. Three of these were thought to have been contracted from close contact with siblings carrying variants of influenza B with the same mutation and the remainder contracted within the community. This is in contrast to the influenza A virus, which has exhibited generations of drug-resistant variants in 5.5-18\% of cases, found in other studies.

The study shows that influenza B viruses are far less likely to have developed reduced sensitivity to neuraminidase inhibitors than influenza A viruses. However, once present, the mutant variants may be contracted both within families and the community. It is possible that widespread use of oseltamivir may have caused the generation of these mutant variants in the community.

Although influenza B causes smaller epidemics than influenza A, and the clinical course of infection does not appear to be affected by the mutations, ongoing surveillance for the development of neuraminidase inhibitor resistant influenza viruses is critical. 